\title{
ANALISIS KELENGKAPAN PENGISIAN DATA FORMULIR ANAMNESIS DAN PEMERIKSAAN FISIK KASUS BEDAH
}

\author{
Rd. Irda Melinda Febriyanti ${ }^{1}$, Ida Sugiarti ${ }^{2}$ \\ ${ }^{1}$ Alumni Program Studi D III PIKES Poltekkes Kemenkes Tasikmalaya, ${ }^{2}$ Dosen Program Studi D III \\ PIKES Poltekkes Kemenkes Tasikmalaya \\ Email : sugiarti.ida@gmail.com
}

\begin{abstract}
Quantitative analysis has conducted in dr. Slamet Garut General Hospital, but there are still anamnesis and physical examination forms are incomplete both clinical data and demographic data. Based on the highest preliminary survey of incompleteness on the register component is $83.34 \%$. The aim of this research is to know the fulfilment procedure, completeness and incompleteness data fulfilment of anamnesis and physical examination forms. The method that used in this research is observation quantitative analysis, using instrument observation sheet. The population in this research are 1008 medical record documents on semester I in 2013. The magnitude of the sample uses Slovin formula is 90 documents. Slovin formula is used because it refers to large samples which are 90 documents. The result of research showed that complete form anamnesis and physical examination of the patient identification component is $20 \%$, important report is $31.12 \%$, authentication is $83.33 \%$ dan the register is $3.34 \%$. Refers to the minimum standard of completeness which is submitted by the department of health (2006), the completeness document must be 100\%. It can be conclusion that the anamnesis and physical examination data fulfilment in dr. Slamet Garut General Hospital is not complete. Preferably, socialization is needed in fulfilment medical record document which is adapted to the Standard Operational Procedure (SOP) or The Fixed Procedure (PROTAP) which is adapted to all units related personal health such as doctors, nurses, dan medical record officer.
\end{abstract}

Key words : Completeness, Filling up data, Anamnesis and physical examination.

\begin{abstract}
Abstrak
Di RSUD dr. Slamet Garut sudah dilakukan analisis kuantitatif tetapi masih terdapat formulir anamnesis dan pemeriksaan fisik yang kurang lengkap baik data demografi maupun data klinis. Berdasarkan survey pendahuluan ketidaklengkapan yang tertinggi pada komponen pencatatan 83,34\%. Tujuan penelitian ini untuk mengetahui prosedur pengisian, kelengkapan dan ketidaklengkapan pengisian data formulir anamnesis dan pemeriksaan fisik. Penelitian ini menggunakan metode analisis kuantitatif yaitu observasi, dengan menggunakan instrumen lembar observasi. Populasi dalam penelitian ini sebanyak 1008 dokumen rekam medis pada semester I tahun 2013. Besarnya sampel menggunakan rumus Slovin sebanyak 90 dokumen. Hasil penelitian menunjukan kelengkapan formulir anamnesis dan pemeriksaan fisik komponen identifikasi pasien sebanyak $20 \%$, laporan penting 31,12\%, authentikasi $83,33 \%$ dan pencatatan 3,34\%. Mengacu pada standar minimal kelengkapan dokumen yang diajukan departemen kesehatan (2006) kelengkapan dokumen harus 100\%. Maka dapat disimpulkan pengisian data formulir anamnesis dan pemeriksaan fisik di RSUD dr. Slamet Garut tidak lengkap. Sebaiknya, diadakan sosialisasi dalam pengisian dokumen rekam medis disesuaikan dengan Standar Operasional Prosedur (SOP) at au Prosedur Tetap (PROTAP) yang telah ditetapakan pada semua unit pelayanan kepada tenaga kesehatan terkait seperti : dokter, perawat dan petugas rekam medis.
\end{abstract}

Kata Kunci: Kelengkapan, Pengisian data, Anamnesis dan Pemeriksaan Fisik 


\section{PENDAHULUAN}

Rekam medis mempunyai pengertian yang sangat luas, tidak hanya sekedar kegiatan pencatatan, akan tetapi mempunyai pengertian sebagai suatu sistem penyelenggaraan rekam medis yaitu mulai pencatatan selama pasien mendapatkan pelayanan medik, dilanjutkan dengan penanganan berkas rekam medis yang meliputi penyelenggaraan penyimpanan serta pengeluaran berkas dari tempat penyimpanan untuk melayani permintaan/peminjaman, apabila dari pasien atau untuk keperluan lainnya.

Rekam medis diartikan sebagai keterangan baik yang tertulis maupun terekam tentang identitas, anamnese, pemeriksaan fisik, laboratorium, diagnosa serta segala pelayanan dan tindakan medis yang diberikan kepada pasien, dan pengobatan baik yang dirawat inap, rawat jalan maupun yang mendapatkan pelayanan gawat darurat (Depkes, 2006).

Setiap dokter atau dokter gigi dalam menjalankan praktik kedokteran wajib membuat rekam medis (Undang - Undang RI No 44 tahun 2009 tentang Praktik Kedokteran pasal 46). Karena rekam medis merupakan catatan dan dokumen semua tindakan serta pelayanan yang diberikan kepada pasien maka pengisian rekam medis harus lengkap agar informasi menjadi akurat.

Ketidaklengkapan dalam pengisian data rekam medis akan memberikan dampak yang tidak baik pada proses pelayanan kesehatan. Setiap tenaga kesehatan, baik itu dokter maupun tenaga kesehatan lainnya berkewajiban untuk melaksanakan pelayanan kesehatan yang optimal.

Analisis kuantitatif adalah analisis yang ditunjukkan kepada jumlah lembaran-lembaran rekam medis sesuai dengan lamanya perawatan meliputi kelengkapan lembaran rekam medis, paramedis dan penunjang medis sesuai prosedur yang ditetapkan (Depkes, 2006). Analisis kuantitatif terdiri dari 4 komponen yaitu review identifikasi, review pelaporan penting, review authentikasi dan review pencatatan. Kelengkapan dokumen rekam medis sangat penting agar informasi yang dihasilkan dapat berkesinambungan.

Kelengkapan dokumen rekam medis dibutuhkan pada pelayanan di Rumah Sakit, terutama kasus yang beresiko seperti tindakan-tindakan invasif di Ruang bedah. Ruang bedah atau kamar operasi adalah bagian dari sebuah pelayanan rumah sakit yang diperlukan untuk memberikan sarana dan prasarana tindakan bedah. Karena kasus bedah merupakan kasus yang beresiko tinggi maka akan memerlukan data yang lengkap agar tidak terjadi hal-hal yang tidak diinginkan misalnya kasus malpraktik yang bisa masuk ke ranah hukum.

Formulir yang ada di ruang bedah terdiri dari formulir anamnesis dan pemeriksaan fisik, surat pernyataan persetujuan tindakan/anestesi,surat pernyataan pulang paksa, surat persetujuan tindakan medis, follow-up dokter, pengkajian data keperawatan bedah, laporan operasi, resume keperawatan, rekaman asuhan keperawatan, grafik suhu - nadi, surat kontrol, resume diagnosa akhir, tindakan keperawatan dan catatan perkembangan.

Salah satu formulir yang ada di ruang bedah adalah formulir anamnesis dan pemeriksaan fisik. Anamnesis adalah salah satu teknik pemeriksaan yang dilakukan lewat suatu percakapan antara seorang dokter atau perawat dengan pasiennya sevara langsung atau dengan orang lain yang mengetahui tentang kondisi pasien, untuk mendapatkan data pasien beserta permaslahan medisnya. Pemeriksaan fisik merupakan bagian integral dari pengkajian keperawatan. Pemeriksaan fisik biasanya dilakukan setelah riwayat kesehatan dikumpulkan (Waluyo, 2001). Pencatatan riwayat kesehatan pasien pada formulir anamnesis dan pemeriksaan fisik harus dicatat dengan lengkap karena formulir tersebut untuk menetapkan diagonis selanjutnya.

Berdasrakan survey pendahuluan yang peneliti lakukan pada tanggal 11 Februari 2014 di RSUD dr. Slamet Garut ditemukan formulir anamnesis dan pemeriksaan fisik yang belum lengkap. Peneliti mengambil 30 dokumen pada kasus bedah umum untuk dianalisis kelengkapannya, setelah dokumen tersebut dianalisis masih terdapat formulir anamnesis dan pemeriksaan fisik yang kurang lengkap baik itu dari data demografi maupun data klinis. Setelah dipresentasikan pada 30 formulir anamnesis dan pemeriksaan fisik untuk identifikasi pasien pada item jenis kelamin yang lengkap sebesar $16.6 \%$ dan tidak lengkap sebesar $83.3 \%$, laporan penting pada item status lokasi yang lengkap sebesar $40 \%$ dan tidak lengkap sebesar $60 \%$, authentikasi pada item nama dokter yang lengkap sebesar $73.3 \%$ dan tidak lengkap $26.6 \%$ dan pencatatan pada item jam yang lengkap sebesar $16.6 \%$ dan tidak lengkap $83.3 \%$. Dilihat dari data laporan jumlah tindakan operasi di RSUD dr. Slamet Garut tahun 2013 menunjukan bahwa angka 
kasus bedah semester I sebanyak 1008 dibandingkan dengan semester II sebanyak 977.

Tabel 1. Tabel Jumlah tindakan operasi RSUD dr. Slamet Garut

\begin{tabular}{clcc}
\hline No & \multicolumn{1}{c}{ SMF } & Semester I & Semester II \\
\hline 1 & Bedah & 1008 & 977 \\
2 & Orthopedi & 336 & 335 \\
3 & Obgyn & 1734 & 1885 \\
4 & Mata & 133 & 110 \\
5 & THT & 95 & 93 \\
\hline
\end{tabular}

Berdasarkan uraian diatas, peneliti mengambil penelitian dengan judul “ Analisis Kelengkapan Pengisian Data Formulir Anamnesis dan Pemeriksaan Fisik Kasus Bedah di Rumah Sakit Umum Daerah dr. Slamet Garut Semester I tahun 2013"

\section{METODE}

Jenis penelitian yang digunakan adalah penelitian deskriptif (Azwar, 2001 dalam Siswanto, 2013) yaitu melakukan analisis hanya sampai pada taraf deskripsi, yaitu menganalisa dan menyajikan fakta secara sistematik sehingga dapat lebih mudah untuk dipahami dan disimpulkan. Penelitian deskriptif bertujuan menggambarkan secara sistematik dan akurat fakta dan karakteristik mengenai populasi atau mengenai bidang tertentu.

Desain penelitian yang digunakan adalah kuantitatif yaitu penelitian dengan menekankan analisisnya pada data-data numerikal (angka) yang diolah dengan metoda statistika (Azwar, 2001 dalam Siswanto, 2011) yaitu analisis kelengkapan pengisian data formulir anamnesis dan pemeriksaan fisik kasus bedah.

Penelitian dilaksanakan di Instalasi Rekam Medis RSUD dr. Slamet Garut tanggal 7 Mei - 13 Juni 2014.

Pada penelitian ini populasi yang digunakan sebanyak 1008 dokumen rekam medis pada semester I tahun 2013. Penentuan besarnya sampel (Sample Size) dalam penelitian ini menggunakan rumus perhitungan dari Slovin (Siswanto, dkk. 2013) :

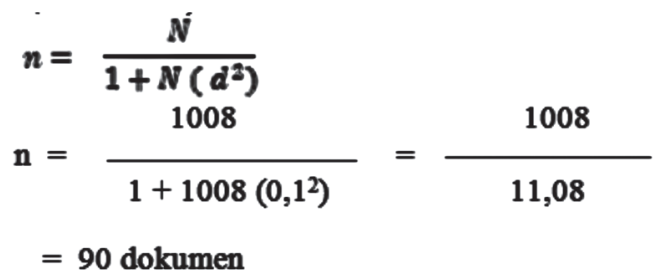

Keterangan :

$$
\begin{aligned}
\mathrm{n}= & \text { Jumlah Sampel } \\
\mathrm{N}= & \text { Jumlah Populasi } \\
\mathrm{d}^{2}= & \text { Presisi (ditetapkan 10\% dengan tingkat } \\
& \text { kepercayaan 95\%). }
\end{aligned}
$$

Teknik pengambilan sampling menggunakan cara pengambilan sampel secara acak sederhana, dengan cara mengundi anggota populasi atau teknik undian. Teknik undian ini dilakukan dengan menggunakan bantuan perangkat lunak komputer yaitu microsoft excel (Subasman, 2012).

Kriteria inklusi adalah kriteria atau ciri-ciri yang perlu dipenuhi oleh setiap anggota populasi yang dapat diambil sebagai sampel sedangkan kriteria eksklusi adalah ciri-ciri anggota populasi yang tidak dapat diambil sebagai sampel (Notoatmodjo, 2010).

\section{Kriteria Inklusi}
a. Identifikasi
b. Pelaporan yang penting
c. Otentikasi
d. Pencatatan

\section{Kriteria Ekslusi}

\section{a. Cara pencatatan berdasarkan kebenaran penulisan}

Penelitian ini bersifat univariat yang berarti terdapat satu variabel yang diteliti yaitu analisis kelengkapan pengisian data formulir anamnesis dan pemeriksaan fisik.

Instrumen yang digunakan adalah lembar observasi dengan melihat secara langsung rekam medis pasien terutama formulir anamnesis dan pemeriksaan fisik yang tidak lengkap dalam pengisiannya.

Observasi adalah suatu prosedur yang berencana, yang antara lain meliputi melihat, mendengar, dan mencatat sejumlah taraf aktivitas tertentu atau situasi tertentu yang ada hubungannya dengan masalah yang diteliti. Alat observasi yang digunakan adalah lembar observasi yaitu suatu daftar untuk men"cek" yang berisi nama subjek dan beberapa gejala serta identitas lainnya dari sasaran pengamatan (Notoatmodjo, 2012). 


\section{HASIL}

Berdasarkan data yang diperoleh dari hasil penelitian pada dokumen rekam medis pasien rawat inap kasus bedah pada semester 1 tahun 2013 untuk kelengkapan pengisian data formulir anamnesis dan pemeriksaan fisik dengan jumlah dokumen yang diteliti sebanyak 99 dapat disajikan pada tabel berikut :

Tabel 1. Distribusi Frekuensi Identitas Pasien pada formulir anamnesis dan pemeriksaan fisik kasus bedah di RSUD dr. Slamet Garut semester 1 tahun 2013

\begin{tabular}{llc}
\hline \multicolumn{1}{c}{ Pengisian kelengkapan } & F & \% \\
\hline Lengkap & 18 & 20 \\
Tidak lengkap & 72 & 80 \\
\hline Jumlah & 90 & 100 \\
\hline
\end{tabular}

Berdasarkan tabel 1 diatas menunjukan kelengkapan identifikasi pasien pada formulir anamnesis dan pemeriksaan fisik dengan item nama pasien, nomor rekam medis, umur pasien dan jenis kelamin di dapatkan hasil bahwa kelengkapan pengisian data identifikasi pasien yaitu 18 formulir (20\%). Sedangkan persentase ketidaklengkapan pengisian data identifikasi pasien yaitu 72 formulir (80\%).

Tabel 2. Distribusi Frekuensi Laporan Penting Pada Formulir Anamnesis dan pemeriksaan fisik kasus bedah di rsud dr. Slamet garut semester 1 tahun 2013.

\begin{tabular}{lcc}
\hline Pengisian kelengkapan & F & \% \\
\hline Lengkap & 28 & 31,12 \\
Tidak lengkap & 62 & 68,88 \\
\hline Jumlah & 90 & 100 \\
\hline
\end{tabular}

Berdasarkan tabel 2 di atas menunjukan kelengkapan laporan penting pada formulir anamnesis dan pemeriksaan fisik dengan item keluhan utama, keadaan, kesadaran, kepala, thorax, abdomen, status lokasi dan diagnosa kerja di dapatkan hasil bahwa kelengkapan pengisian data laporan penting pasien yaitu 28 formulir $(31,12 \%)$. Sedangkan persentase ketidaklengkapan pengisian data laporan penting yaitu 62 formulir $(68,88 \%)$.

Tabel 3. Distribusi Frekuensi authentikasi pada formulir anamnesis dan pemeriksaan fisik kasus bedah

di RSUD dr. Slamet Garut semester 1 tahun 2013

\begin{tabular}{|c|c|c|}
\hline Pengisian kelengkapan & $\mathbf{F}$ & $\%$ \\
\hline Lengkap & 75 & 83,33 \\
\hline Tidak lengkap & 15 & 16,67 \\
\hline Jumlah & 90 & 100 \\
\hline
\end{tabular}

Berdasarkan tabel 3 di atas menunjukan kelengkapan authentikasi pada formulir anamnesis dan pemeriksaan fisik dengan item nama dokter dan tanda tangan dokter di dapatkan hasil bahwa kelengkapan pengisian data authentikasi yaitu 75 formulir $(83,33 \%)$. Sedangkan persentase ketidaklengkapan pengisian data laporan penting yaitu 15 formulir $(16,67 \%)$.

Tabel 4. Distribusi Frekuensi pencatatan pada formulir anamnesis dan pemeriksaan fisik kasus bedah di RSUD dr. Slamet Garut semester 1 tahun 2013

\begin{tabular}{|c|c|c|}
\hline Pengisian kelengkapan & $\mathbf{F}$ & $\%$ \\
\hline Lengkap & 3 & 3,34 \\
\hline Tidak lengkap & 87 & 96,66 \\
\hline Jumlah & 90 & 100 \\
\hline
\end{tabular}

Berdasarkan tabel 4 di atas menunjukan kelengkapan pencatatan pada formulir anamnesis dan pemeriksaan fisik dengan item tanggal, jam dan gedung di dapatkan hasil bahwa kelengkapan pengisian data pencatatan yaitu 3 formulir (3,34\%). Sedangkan persentase ketidaklengkapan pengisian data laporan penting yaitu 87 formulir $(96,66 \%)$.

\section{PEMBAHASAN}

Pengertian dokumen rekam medis menurut PerMenKes No.269/Menkes/Per/III/2008 pasal 1 adalah catatan dokter, dokter gigi, dan tenaga kesehatan tertentu berisi formulir ringkasan masuk dan keluar, anamnesis, laporan operasi, laporan hasil pemeriksaan penunjang, catatan observasi dan pengobatan harian dan semua rekaman baik berupa foto radiologi. Dokumen rekam medis berisi data individual yang bersifat rahasia. Maka setiap dokumen rekam medis harus dilindungi dengan cara memasukan ke dalam map dan disimpan.

Formulir Rekam Medis yaitu sebagai suatu bentuk lembaran catatan dengan kolom-kolom di dalamnya yang harus diisi dengan angka-angka, jawabanjawaban, at aupun keterangan-keterangan yang sesuai dengan pertanyaan atau instruksi yang ada. Terdapat bermacam-macam bentuk formulir rekam medis yang dipakai oleh rumah sakit, namun semuanya harus memenuhi keperluan-keperluan yang mendasar. Formulir-formulir rekam medis sendiri tidak memberikan jaminan pencatatan data medik yang tepat dan benar, apabila para dokter maupun staf mediknya tidak secara seksama melengkapi 
informasi yang diperlukan pada setiap lembaran rekam medis dengan baik dan benar.

Di Rumah Sakit Umum dr Slamet Garut sudah dilakukan analisis kuantitatif dokumen rekam medis, jika ada dokumen rekam medis yang tidak lengkap akan dikembalikan lagi ke ruangan untuk dilengkapi oleh dokter atau perawat yang mengisi dokumen rekam medis tersebut, tetapi pengembalian dokumen rekam medis yang belum lengkap dari ruangan perawatan sangat lama, sehingga pihak dari rekam medis tidak lagi mengembalikan dokumen yang tidak lengkap ke ruangan perawatan, dan langsung di simpan ke tempat penyimpanan dokumen rekam medis. Untuk pengisian kelengkapan identifikasi dokumen rekam medis, petugas rekam medis melengkapi identitas dokumen rekam medis yang belum lengkap. Di RSUD dr. Slamet Garut tidak dibuat standar operasional prosedur (SOP) tentang pengisian data formulir anamnesis dan pemeriksaan fisik secara khusus tetapi prosedur pengisian data yang ada hanya secara umum/ keseluruhan untuk setiap formulir yang ada pada dokumen rekam medis. Pada umumnya prosedur pengisian data dokumen rekam medis harus ada untuk setiap formulir yang ada di dalam dokumen rekam medis agar memudahkan petugas dalam pengisian data formulir.

Berdasarkan hasil penelitian analisis kelengkapan pengisian data formulir anamnesis dan pemeriksaan fisik yang meliputi 4 komponen yaitu identifikasi pasien, laporan penting, authentikasi dan pencatatan dokumen rekam medis dapat dilihat kelengkapan pada pengisian data diantaranya :

\section{Kelengkapan Identifikasi pasien}

Hasil penelitian menunjukan bahwa masih terdapat formulir rekam medis anamnesis dan pemeriksaan fisik yang terisi tidak lengkap. kelengkapan identifikasi pasien pada formulir anamnesa dan pemeriksaan fisik dengan item nama pasien, nomor rekam medis, umur pasien dan jenis kelamin diantaranya sebanyak 18 formulir yang terisi dengan lengkap dengan persentase $(20 \%)$ sedangkan untuk ketidaklengkapan atau formulir yang terisi tidak lengkap sebanyak 72 formulir dengan persentase (80\%). Angka ketidaklengkapan ini dianggap sebagai masalah yang serius.

Kelengkapan pengisian identifikasi ini belum sesuai dengan SOP yang ada di Rumah
Sakit Umum Daerah dr. Slamet Garut. Salah satunya pada item jenis kelamin tidak terisi dengan lengkap. Jenis kelamin ini berpengaruh terhadap diagnosa. Dokumen rekam medis dikatakan lengkap apabila semua data yang ada di dalamnya terisi dengan lengkap dan benar sesuai dengan prosedur pengisian yang telah ditetapkan oleh rumah sakit. Khususnya kelengkapan identitifikasi pasien yang bertujuan untuk memastikan apakah dokumen rekam medis milik pasien yang bersangkutan (Hatta, 2006).

\section{Kelengkapan Laporan Penting}

Hasil kelengkapan laporan penting pada formulir anamnesa dan pemeriksaan fisik dengan item keluhan utama, keadaan, kesadaran, kepala, thorax, abdomen, status lokasi, diagnosa kerja diantaranya formulir yang terisi lengkap sebanyak 28 formulir dengan persentase $31,12 \%$ sedangkan formulir yang terisi tidak lengkap sebanyak 62 formulir dengan persentase $68,88 \%$.

Pengisian laporan penting ini harus terisi dengan lengkap karena laporan penting ini diperlukan terhadap perjalanan penyakit pasien dan untuk menentukan diagnosis selanjutnya. Pengisian yang terisi tidak lengkap paling tinggi yaitu pada item status lokasi. Ketidaklengkapan pada item status lokasi ini sebesar 56,66\%. Apabila laporan ini tidak terisi lengkap maka tidak akan ada pengobatan dan tindakan selanjutnya sedangkan ini pada kasus bedah yang beresiko tinggi. Informasi pemeriksaan fisik yang objektif ini harus tersedia dalam rekam kesehatan pasien dalam waktu 24 jam sejak pasien terdaftar sebagai pasien masuk. Tanpa informasi pemebedahan tidak dapat terlaksana (McCain, 2002).

\section{Kelengkapan Authentikasi}

Kelengkapan authentikasi pada formulir anamnesa dan pemeriksaan fisik dengan item nama dokter dan tanda tangan dokter diantaranya formulir yang terisi lengkap sebanyak 75 formulir dengan persentase $83,33 \% \%$ sedangkan formulir yang terisi tidak lengkap sebanyak 15 formulir dengan 
persentase $16,67 \%$. Pengisian authentikasi harus di isi dengan lengkap, terutama pada kasus atau tindakan yang beresiko tinggi, harus terdapat tanda tangan dari pihak dokter maupun pemberi persetujuan lainnya. Apabila dalam pengisian authentikasi tidak lengkap ini merupakan salah satu ketidakdisiplinan dan tanggung jawab pihak dokter.

Menurut Huffman tahun 1994, authentikasi dapat berupa tanda tangan, stempel milik pribadi, initial (singkatan nama) atau kode akses komputer. Sehingga dapat memudahkan identifikasi dalam rekam medis. Tidak boleh ditandatangani oleh orang lain selain penulis, kecuali bila ditulis oleh dokter jaga atau mahasiswa. Maka dari itu, apabila dokumen belum ditandatangani khususnya formulir anamnesis dan pemeriksaan fisik, pet ugas rekam medis harus segera mengembalikan ke ruangan agar dokter untuk melengkapi formulir tersebut.

\section{Kelengkapan pencatatan}

Pencatatan yang baik ataupun jelas sangat diperlukan, untuk memudahkan para pembaca peneliti kelengkapan dokumen rekam medis. Pencatatan kegiatan pelayanan medis tentang ketentuan pengisian rekam medis. Bahwa penghapusan tulisan dengan cara apapun tidak diperbolehkan (Depkes, 2006).

Berdasarkan hasil penelitian kelengkapan pencatatan pada formulir anamnesa dan pemeriksaan fisik dengan item tanggal, jam dan gedung diantaranya formulir yang terisi lengkap sebanyak 3 formulir dengan persentase 3,34\% sedangkan formulir yang terisi tidak lengkap sebanyak 87 formulir dengan persentase $96,66 \%$. Ketidaklengkapan tersebut terutama pada item tanggal dapat mempengaruhi untuk menentukan biaya hari perawatan di rumah sakit.

Berdasarkan hasil penelitian analisis kuantitatif unt uk pengisian data formulir anamnesis dan pemeriksaan fisik dari ke 4 komponen tersebut bahwa kelengkapan yang tertinggi atau terisi lengkap terdapat pada komponen authentikasi dengan persentase $83,33 \%$ dan kelengkapan yang terendah terdapat pada komponen pencatatan dengan persentase 3,34\%.
Sedangkan ketidaklengkapan yang tertinggi terdapat pada komponen pencatatan dengan persentase $96,66 \%$ dan ketidaklengkapan yang terendah terdapat pada komponen authentikasi dengan persentase $16,67 \%$.

Sehingga dengan ketidaklengkapan tersebut dapat mempengaruhi terhadap kepemilikan dokumen rekam medis dan jika ada formulir yang tercecer atau terlepas dari mapnya akan menyulitkan petugas rekam medis untuk menggabungkan, Jika suatu saat formulir tersebut dibutuhkan. Ini terjadi diakibatkan banyak faktor, namun secara keseluruhan faktor kesadaran dan kedisiplinan petugas penanggung jawab pengisian data formulir sangat mendominasi tidak terisinya formulir tersebut.

\section{SIMPULAN}

Berdasarkan hasil penelitian dan pembahasan yang telah disampaikan pada bab sebelumnya, maka simpulan yang dapat penulis sampaikan yaitu pengisian data dokumen rekam medis di RSUD dr. Slamet Garut masih belum sesuai dengan SOP yang telah ditetapkan oleh rumah sakit khususnya yang meliputi 4 komponen yaitu identifikasi pasien, laporan penting, authentikasi dan pencatatan.

1. Kelengkapan Identifikasi Pasien

Kelengkapan pengisian data identifikasi pasien yaitu 18 formulir (20\%). Sedangkan presentase ketidaklengkapan pengisian data identifikasi pasien yaitu 72 formulir (80\%).

2. Kelengkapan Laporan Penting

Kelengkapan pengisian data laporan penting pasien yaitu 28 formulir (31,12\%). Sedangkan presentase ketidaklengkapan pengisian data laporan penting yaitu 62 formulir $(68,88 \%)$.

3. Kelengkapan Authentikasi

Kelengkapan pengisian data authentikasi yaitu 75 formulir $(83,33 \%)$. Sedangkan presentase ketidaklengkapan pengisian data authentikasi yaitu 15 formulir $(16,67 \%)$.

\section{DAFTAR PUSTAKA}

Astutik, D, I. (2011). Teknik Pemeriksaan Fisik. Diakses tanggal 11 Maret 2014. http:// ismaiyahdwiastutik.blogspot.com/p/teknikpemeriksaan-fisik.html 
Cinta. Kamar Operasi. Diakses pada tanggal 11 Maret 2014. http://cinta bedah.weebly.com/ kamar-operasi.html

Departemen Kesehatan RI Direktorat Jenderal Bina Pelayanan Medik. (1994). Pedoman Sistem Pencatatan Rumah Sakit. Jakarta : Direktorat Jenderal Bina Yanmed.

Departemen Kesehatan RI Direktorat Jenderal Bina Pelayanan Medik. (2006). Pengelolaan Rekam Medis Rumah Sakit di Indonesia revisi II.Jakarta : Direktorat Jenderal Bina Yanmed.

Hatta, G. (2010). Pedoman Manajemen Informasi Kesehatan di Sarana Pelayanan Kesehatan. Jakarta : Universitas Indonesia.

Huffman, Edna K. (1994). Health Information Management. Berwyn Illinois: Physicians Record Company.

Kumala, P. Et. Al (edt). (1998). Kamus Saku Kedokteran Dorlan Edisi Bahasa Indonesia. Jakarta : EGC.

Maulana, R. (2008). Anamnesis. Dipublikasikan 2 Desember 2008. Diakses pada tanggal 4 Maret 2014.

Notoatmodjo, Soekidjo. 2012. Metodologi Penelitian Kesehatan. Jakarta: PT Rineka Cipta.

Nursalam. (2011). Manajemen Keperawatan. Jakarta : Salemba Medika.
Peraturan Menteri Kesehatan RI. 2008. Peraturan Menteri Kesehatan Republik Indonesia Nomor: 269/Menkes/Per/III/2008 tentang Rekam Medis. Jakarta: Menteri Kesehatan RI.

Subasman, Iman. (2012). Membuat Tabel Acak dengan Excel. [Online]. Tersedia di http:// imansubasman.blogspot.com/2012/11/ membuat-tabel-acak-dengan-excel.html.[31 Maret 2014]

Shofari, Bambang. 2002. Modul Pembelajaran Pengelolaan Rekam Medis dan Dokumentasi rekam medis. Semarang: PORMIKI

Siswanto, Susila, \& Suyanto. (2013). Metodologi Penelitian Kesehatan dan Kedokteran. Yogyakarta : Bursa Ilmu.

Sugiyono. (2008). Statistika Untuk Penelitian. Bandung: CV Alfabeta.

Sugiyono. (2009). Metodologi Penelitian Kuantitatif Kualitatif dan R \& D. Bandung : CV Alfabeta.

Waluyo, A. Et. Al (Edt). (2001). Keperawatan Medical-bedah Brunner Suddarth Edisi Bahasa Indonesia. Jakarta : EGC.

Undang - Undang Praktik Kedokteran . (2011). Undang-Undang Kedokteran. Bandung : Fokuskindo Mandiri. 